\title{
Ulumuddin: Jurnal Ilmu-ilmu Keislaman
}

(p)ISSN: 1907-2333 (e)ISSN: 2685-9211

https://jurnal.ucy.ac.id/index.php/agama_islam

Volume 9 Nomor 2, Desember 2019, 97-112

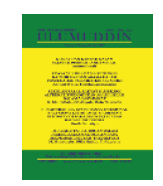

\section{IDEOLOGI PENDIDIKAN \\ PONDOK PESANTREN AL-ISLAM \\ TENGGULUN SOLOKURO LAMONGAN}

\author{
Taufik Nugroho*) \\ FAI Unversitas Cokroaminoto \\ taufikn325@gmail.com
}

*Penulis koresponden

\begin{tabular}{|l|l|l|}
\hline Diajukan: 23-12-2019 & Diterima: 18-02-2020 & Diterbitkan: 24-02-2020 \\
\hline
\end{tabular}

\begin{abstract}
This research is motivated by the fact that there are some pesantren alumni and caregivers involved in radicalism. Based on the facts above, the researcher is interested in conducting research on the ideological aspects. Many people believe that a person's actions are guided and validated by the ideology he believes in. For this reason the question arises, 'what is the ideology of education in the pesantren al-Islam, Tenggulun, Solokuro? "To answer that question, the researcher investigates information in the pesantren by participating; participated in a number of activities at the pesantren. The information to be sought is: our book / study material, curriculum and its implementation in learning. The results of the investigation are as follows: The ideology of alIslam Islamic Boarding School education is theo-centric humanism. This pesantren does not refer to classical books that are not patient, but studies of Islamic harakah. Building a narrative of conflict and conquest in religious teachings. The learning implemented by the pesantren is carried out in three stages, first tarbiyah, second, hijrah and third jihad.
\end{abstract}

keywords: theo-centrism, tarbiyah, hijrah, jihad

\begin{abstract}
Abstrak: Penelitian ini dilatarbelakangi oleh fakta bahwa ada sebagian alumni pesantren dan pengasuhnya terlibat dalam tindak radikalisme. Berdasar pada fakta-fakta di atas, maka peneliti tertarik untuk melakukan penelitian pada aspek ideologinya. Diyakini banyak orang bahwa tindakan seseorang dituntun dan diabsahkan oleh ideologi yang diyakininya. Untuk itu muncul pertanyaan, 'apa ideologi pendidikan pesantren al-Islam, Tenggulun, Solokuro? ".Untuk menjawab pertanyaan tersebut, peneliti melakukan investigasi informasi di pesantren tersebut dengan cara partisipasi; mengikuti sejumlah kegiatan di pesantren tersebut. Informasi yang hendak dicari adalah: kitab-kita/bahan kajian, kurikulum dan implementasinya dalam pembelajaran. Hasil investigasi tersebut adalah sebagai berikut: Ideologi pendidikan PP al-Islam adalah humanisme theocentris. Pesantren ini tidak merujuk Kitab-kitab klasik yang mu'tabar, tetapi kajian harakah Islamiyah. Membangun narasi konflik dan penaklukan dalam ajaran agama. Pembelajaran yang diimplementasikan pesantren tersebut dilakukan dengan tiga tahap, pertama tarbiyah, kedua,
\end{abstract}


hijrah dan ketiga jihad.

Kata kunci: teosentrisme, tarbiyah, hijrah dan jihad.

\section{A. Pendahuluan}

Lembaga pendidikan Islam di Indonesia yang dinilai asli adalah pondok pesantren. ${ }^{1}$ Selama ini telah dikenal menjadi tempat untuk pembinaan moral kesalehan santri dan pembelajaran ilmu-ilmu agama Islam serta pusat penyebaran Islam di pedesaan. Di era kolonial menjadi basis persemaian sikap oposisi dan perlawanan terhadap penjajah yang tidak seagama untuk kemerdekaan bangsa. Hal itu terbukti dengan ada sejumlah pemberontakan terhadap penjajah Belanda yang dimotori oleh kyai pimpinan pesantren.

Pada era post kemerdekaan, lembaga pendidikan asli telah berubah wajah. Kembali kepada jalur utama, persemaian dan dakwah ajaran Islam ditekankan, pembinaan anak bangsa yang saleh nasionalis dengan penuh kedamaian. Semua fakta di atas adalah catatan ringkas tentang prestasi pesantren dan sumbangannya kepada bangsa Indonesia. ${ }^{2}$

Keakraban pesantren dengan ide-ide kebangsaan ternyata telah mengalami jalan terjal dewasa ini. faham radikalisasi pemikiran keagamaan telah menggejala. 3 Walaupun jumlahnya kecil dan sering diposisikan sebagai kelompok yang terpinggirkan secara ekonomi dan politik, tetapi kelompok ini memiliki militansi luar biasa, 4

Pemikiran Islam bidang politik itu dapat juga disebut sebagai Islamisme. 5 Para penggiatnya menempatkan Islam bukan hanya sebagai sistem ibadah (ritual; shalat, zakat, puasa dan haji), tetapi Islam telah

${ }^{1}$ Umi Musaropah, "Kharisma Kyai Dalam Organisasi Pendidikan Pesantren Tradisional," Ulumuddin : Jurnal Ilmu-ilmu Keislaman 8, no. 2 (2018): 141-155; Taufik Nugroho, "Reorientasi Peranan Pesantren Pada Era Pembangunan Menuju Partisipasi Pemberdayaan Masyarakat Bawah," Ulumuddin : Jurnal Ilmu-ilmu Keislaman 7, no. 2 (2017): 147-155.

2 Imroatun, "Kontribusi Lembaga Pendidikan Agama Islam Dalam Penguatan Identitas Bangsa,” Jurnal Ilmiah Bidang pendidikan Studia Didaktika 8, no. 1 (2016).

3 Direktorat Jenderal Pembinaan Kelembagaan Agama Islam, Pondok Pesantren Dan Madrasah Diniyah Pertumbuhan Dan Perkembangannya (Departemen Agama RI, Direktorat Jenderal Kelembagaan Agama Islam, 2003).

4 Shmuel Bar, "The Religious Sources of Islamic Terrorism."

5 Noorhaidi Hasan, Laskar Jihad (Jakarta: LP3ES-KITLV, 2008), 75. 
mencakup semua aspek kehidupan termasuk sistem politik. Para simpatisannya memiliki aspirasi didengar oleh kelompok mayoritas atau mainstream dengan cara yang berlebihan hingga kontak fisik. Pesan itu ditujukan kepada penguasa global bidang militer, ekonomi dan politik, seperti Amerika Serikat, Inggris serta kawan seiringnya. Negara-negara tersebut harus berbuat adil terhadap saudaran muslim seiman yakni Palestina, Afganistan, Libya dll. Untuk itu sekali lagi, tindakan kekerasan terhadap negara-negara super power beserta seluruh kepentingannya adalah sah adanya, karena itu semua sebagai tindakan balasan. ${ }^{6}$

Pondok Pesantren al-Islam Tenggulun termasuk satu pesantren di atas. Visi dan misi Pondok Pesantren al-Islam, Tenggulun mewujudkan generasi Islam kaffah yakni lulusan yang bersyari'ah Islam. Pondok Pesantren al-Islam Tenggulun membuat miniatur masyarakat Islami dengan memberlakukan syari'ah Islam di lingkungan masyarakat pondok pesantren.

Ideologi pendidikan Islam para penggagasnya dengan latar belakang dan motivasi tersendiri dari Al-Islam dapat dirumuskan beberapa masalah. Pertama, Apa ideologi pendidikan Pondok Pesantren al-Islam, Tenggulun? Kedua, Bagaimana implementasi ideology pendididikan Islam tersebut di Pondok Pesantren al-Islam, Tenggulun?

\section{B. MetodePenelitian}

Penelitian ini memusatkan perhatian pada ideologi pesantren yakni seperangkat ide/gagasan yang memandu, mengendalikan dan menjadi standar evaluasi kegiatan pesantren. Penelitian demikian tidak layak menggunakan model penelitian tindakan kelas.7

${ }^{6}$ Rinaldy Sofwan, "Keluarga Amrozi Dan Jihad Yang Tertunda Dari Lamongan," CNN Indonesia, January 17, 2017. "Islam is My Life, Jihad is My Way."Kalimat itu tertulis di bagian atas pintu kelas Pesantren Al-Islam di Desa Tenggulun, Solokuro, Lamongan, Jawa Timur. Dalam sebuah wawancara dengan CNN Indonesia Chozin Salah satu pengasuh Pondok Pesantren al-Islam mengatakan bahwa setelah sekian lama beraktifitas dengan normal, Al Islam terhentak saat pesantren itu dikaitkan dengan peristiwa Bom Bali. Dua adik kandung Chozin, Amrozi dan Muchlas ditangkap karena diduga terkait Bom Bali. Di sinilah ujian bagi Al Islam.

7 Agung Prihantoro and Fattah Hidayat, "Melakukan Penelitian Tindakan Kelas," Ulumuddin : Jurnal Ilmu-ilmu Keislaman 9, no. 1 (2019): 49-6o. 
Penelitian ini termasuk penelitian kualitatif yang akan menghasilkan data diskriptif naratif tentang tata fikir dan tingkah laku objek studi (para pengasuh, kitab kajian dan para santri) pesantren. Dalam penelitian kualitatif, seorang peneliti berusaha mendiskripsikan situasi, cara berfikir, bersikap dan bertindak objek studi pada situasi yang dialami. 8

Adapun ciri-ciri penelitian kualitatif; pertama, Latar belakang alami, kedua, Bersifat deskriptif. ketiga, Menekankan proses dari pada produk. Keempat, analisa data secara induktif. Kelima, Menginterpretasikan data (meaning). Penelitian induktif memunculkan sesuatu sebagai hasil pengalaman peneliti ketika mengekplorasi data dan menganalisa data. 9

Penelitian pesantren ini bersifat kasuistik yakni kesimpulan yang diperoleh hanya berlaku di pondok pesantren tersebut. Kesimpulan penelitian kental dengan lokalitas, akan tetapi secara akademik dapat dipertanggung jawabkan terkait dengan isu-isu nasional. Creswell menyebut bahwa penelitian studi kasus memiliki ciri-ciri sebagai berikut: 1. Mengidentifikasi kasus, 2. Kasus tersebut terikat oleh tempat dan waktu 3. Peneliti akan banyak mendeskripsikan kontek suatu kasus. Penelitian ini bersifat kualitatif yakni penelitian yang akan menghasilkan teori berbasis data. Penelitian ini tidak membuktikan hipotesis-hipotesis, tetapi bersifat generating theory yang akan menghasilkan teori substantif.

Penelitian ini juga menggunakan pendekatan Verstehen. Alasan utama peneliti menggunakan pendekatan verstehen adalah karena objek penelitian ini adalah manusia dan budayanya. Karena itu pendekatan verstehen dinilai paling tepat untuk meneliti pesantren. Cara kerja pendekatan verstehen yaitu melalui pemahaman. Yang dimakusd dengan pemahaman adalah peneliti berusaha masuk dalam alam berfikir, bersikap dan bertindak objek penelitian. Dengan memasuki alam berfikir tersebut maka peneliti berusaha; memperoleh pengalaman,

8 John W. Creswell, Qualitayive Inquiry and Research Design: Choosing Among Five Traditions (London: Sage Publication Ltd., 1988), 52.

9 Ibid. 
mengekspresikan dan memahami makna sebagaimana dihayati oleh para pelakunya.

\section{Dasar Teori}

1. Ideologi Pendidikan

a. Pengertian

Althusser memberikan pengertian ideologi sebagai berikut: tidak ada masyarakat yang dapat hidup tanpa ideologi. Ideologi menjadi sarana individu atau masyarakat dalam keberlakuan sistem sosial. Ideologi dalam pandangan Althusser tak terpisahkan dari mana manusia memperoleh identitasnya. ${ }^{10}$

Althusser melanjutkan bahwa ideologi bukan saja memiliki eksistensi gagasan tetapi juga eksistensi material yang dipraktikan oleh institusi dalam tindakan nyata, contoh; berdoa, upacara sebelum masuk kelas. Kesemua tindakan tersebut menggambarkan relasi imaginer antara tindakan seseorang atau sekelompok masyarakat dengan ideologi yang dimilikinya. Lebih jauh Althusser mengatakan bahwa ideologi merupakan sistem representasi hubungan antara individu atau sekelompok masyarakat dengan

Ada 3 (tiga) modus operandi suatu ideologi bekerja:

a. Ideologi menggambarkan relasi imajiner antara individu atau sekelompok orang dengan kondisi eksistensinya.

Hal ini artinya ideologi tidak mewakili realitas tetapi insan pendukungnya yang menghidupkan antara dunia dengan dirinya. Inilah ralasi pokok yang digambarkan Althusser sebagai hubungan imajiner antara individu dengan dunia nyata. ${ }^{11} 12$ ia akan melakukan kegiatan secara taratur sesuai dengan tata-cara agama yang anutnya. Dengan demikian, maka individu membangun perilaku secara alamiah mengikuti ideologi yang dianutnya.

b. Interpelasi Ideologi terhadap individu 1969),75.

${ }^{10}$ Louis Althusser, For Marx, trans. Ben Brewster (New York: Pantheon,

${ }^{11}$ Louis Althusser, Tentang Ideologi, Marxisme Strukturalis, Psikoanalisis, Cultural Studies, trans. Olsy Vinoly Arnof (yogyakarta: Jalasutera, 2008), 39. 


\section{Taufik Nugroho}

Yang dimaksud dengan interpelasi ideologi terhadap individu adalah ideology memberikan identitas kepada individu sebagai subjek pendukungnya. Demikianlah, dengan ideology tersebut, subjek mengakui bahwa dirinya sebagai bagian dari pendukungnya.

John B. Thompson mendefinisikan ideology sebagai system simbol yang berkorelasi kuat dengan tindakan. Selanjutnya, Thompson mengatakan bahwa ideology sebagai system ide yang membimbing manusia dalam tindakan, maka ideology harus dikembalikan kepada kepercayaan politik baik bersifat revolusioner, reformasi maupun konservatif. Lebih jauh, Thompson menjelaskan bahwa ideologi mesti berorientasi pada tindakan yang di dalamnya berisi tentang kepercayaan yang terorganisasikan secara koheren 12 William Gamson dalam Klandersmans dkk. mengatakan bahwa ideologi memiliki dua kekuatan utama yakni; membangun opini dan membangun persepsi tentang dunia. ${ }^{13}$

Sementara itu Ali Syariati, seorang arsitek revolusi Iran, mengatakan bahwa ideology adalah penafsiran semua aspek kehidupan tentang individu dan masyarakat. Ideologi menyediakan jawaban atas pertanyaan sebagai berikut: 1. Bagaimana keadaan yang sesunggunya seorang individu ? 2. Apa yang harus dilakukan ? 3. Bagaimana menjadi individu yang seharusnya. Menurut Ali Syariati, ada 3 (tiga ) unsure penting dalam ideologi: 1. Konsepsi ideal tentang manusia, 2. Konsepsi utopia menjadi tujuan yang harus diusahakan, 3. Kemana masyarakat harus bergerak. ${ }^{14}$

b. Kaitan Antara Ideologi dan Pendidikan

HAR Tilar mengatakan bahwa pendidikan mengandung 3 (tiga) unsur, yaitu; 1. Pendidikan adalah tindakan performative yakni membentuk kepribadian yang berwujud pola fikir, sikap dan tindakan. 2.

${ }^{12}$ John B Thompson, Analisis Ideologi: Kritik Wacana Ideologi-Ideologi Dunia, trans. Haqqul Yakin (Yogyakarta: IRCiSoD, 2003), 150.

13 William Gamson, "Political Discourse and Collective Action," in From Structure to Action, Campaign Social Movement Across-Culture, ed. B. Klandersman, H. Kriesi, and S. Torrow (Greenwich: International Social Movement Research Press, 1988), 219255 .

14 Ali Shariati, Man and Islam, trans. Fatollah Marjani (Houston USA: Free Islamic Literature, 1981), 23-25. 
Kepribadian yang terbentuk akibat tindakan pendidikan berguna untuk diri sendiri dan masyarakat. 3. Tindakan pendidikan dituntun oleh system norma yang dipilih oleh pengelola pendidikan dan ditransformasikan kepada peserta didik. ${ }^{15}$

Dari uraian di atas dapat disimpulkan bahwa ideologi pendidikan :

1) Memberikan petunjuk kemana lembaga pendidikan harus berjalan.

2) Memberi standar nilai kepada lembaga pendidikan.

3) Memberi legitimasi bahwa apa yang dilakukan atau dikerjakan sesuai dengan standar nilai ideology tersebut.

4) Menjadi standar evaluasi ketaatan terhadap nilai yang diperjuangkan.

5) Memberi identitas kepada lembaga pendidikan yang menjalankannya.

6) Menyatukan tata nilai sikap dan tindakan bagi para stake holder pendukungnya.

2. Interpretasi untuk aksi

Teori dasar yang digunakan untuk membahas sistem pendidikan Pondok Pesantren al-Islam, Tenggulun adalah teori Kuntowijoyo, Paradigma Islam; interpretasi untuk aksi. Yang dimaksud dengan interpretasi untuk aksi adalah upaya melakukan interpretasi nilai-nilai normative agama Islam untuk melakukan tindakan nyata. ${ }^{16}$ Dengan kata lain, yang dimaksud dengan interpretasi untuk aksi adalah adalah aktivitas mengambil gagasan-gagasan yang bersumber pada al-Qur'an dan hadist untuk diterjemahkan pada praktik-pratik nyata dalam aktivitas kependidikan; mengendalikan orientasi tindakan-tindakan individu atau kelompok dalam dunia pendidikan. Di dalam teori interpretasi untuk aksi terdapat 2 hal pokok yaitu; 1. Aspek ideasional visi teologis Islam 2. Citacita transformasi Islam. Yang dimaksud dengan ideasional visi teologis Islam adalah hal-hal yang paling sentral dalam nilai-nilai Islam. Menurut Kuntowijoyo, aspek paling sentral dalam nilai-nilai Islam adalah Iman.

Surat al-Baqarah ayat ke-2 disebutkan bahwa manusia harus menjadi muttaqin, orang yang beriman atau percaya kepada yang Ghaib.

15 H.A.R. Tilaar, Kekuasaan Dan Pendidikan: Suatu Tinjauan Dari Perspektif Studi Kultural (Magelang: Indonesia Tera, 2003), 123.

${ }^{16}$ Kuntowijoyo, Paradigma Islam, Interpretasi Untuk Aksi (Bandung: Mizan, 1991), 23. 
Kemudian mendirikan shalat dan menunaikann zakat. ${ }^{17}$ Dalam ajaran Islam ada Tri-logi yaitu Iman, Shalat dan Zakat. Hal ini artinya Iman berujung pada amal dan aksi. Selain itu, iman berpusat pada Tuhan tetapi aktualisasinya berujung pada manusia. Lebih jauh, maka tauhid sebagai pusat nilai, pada saat yang sama melihat manusia sebagai transformasi nilai. ${ }^{18}$

Yang dimaksud dengan cita-cita tranformasi Islam adalah ajaran Islam memuat nilai humanisme yang sangat kuat, yakni agama yang mementingkan manusia sebagai tujuan sentral. Namun demikian perlu dicatat bahwa humanism Islam adalah humanism teosentrik. Hal ini artinya Islam adalah agama yang memusatkan ajarannya pada Tuhan, tetapi mengarahkan perjuangannya untuk kemuliaan manusia. Prinsip humanism teosentrik inilah yang diusahakan sebagai nilai yang dihayati sepenuhya dalam masyarakat dan budaya. ${ }^{19}$

Maka dalam teori interpretasi untuk aksi dalam pendidikan Islam mengandung muatan gagasan sebagai berikut:

1. Formulasi Ideology; memuat rasionalisasi dan legitimasi pola perilaku interaksi dalam dunia pendidikan, membangun solidaritas pokok dan identitas social, memberikan petunjuk tindakan yang pasti untuk dilakukan. ${ }^{20}$ Bentuk formulasi tersebut berupa nilai- nilai pendidikan Islam : fitrah manusia, tujuan penciptaan manusia, implikasi fitrah dalam pendidikan.

2. Transformasi, yakni; aktivitas nyata dalam rangka desimenasi nilainilai pendidikan Islam pada para santri. Di dalamnya terkandung unsure: kurikulum, kompetensi dasar, strategi pencapaian pembelajaan.

\section{Akar Ideologi Pendidikan}

1. Kritik Pendidikan Kontemporer

${ }_{17}$ Kementerian Agama RI., Al-Qur'an Dan Terjemahnya (Jakarta: PT.Sinergi Pustaka Indonesia, 2012).

18 Kuntowijoyo, Paradigma.

19 Ibid.

20 Ibid. 
Sejumlah informasi menunjukkan bahwa al-Islam melakukan evaluasi kritis terhadap system pendidikan nasional secara umum. Paradigma pendidikan nasional, yang diikuti oleh lembaga-lembaga pendidikan Islam seakrang dianggap masih mengikuti paradigma Barat.

Secara ringkas paradigma pendidikan Barat berpusat pada eksistensialisme manusia. Pendidikan Barat menekankan pada manusia, tetapi bersifat sekuler. Sementara itu, pendidikan Islam mengarahkan anak didik menjadi insan yang mengabdi kepada Allah swt ('Abdullah) dan menjadi khalifah di muka bumi (khalifah fil-Ardhy). ${ }^{21}$

Pondok Tenggulun menilai bahwa pendidikan kontemporer adalah produk pendidikan kultur Barat, yang sebagian diikuti oleh sejumlah lembaga pendidikan Islam. Implikasinya adalah bahwa lulusan pendidikan tersebut mengikuti pola fikir dan cara pandang Barat. Akibat lebih jauh adalah dunia Islam hampir-hampir tercerabut dari akar budaya Islam.

Pendidikan kontemporer yang menghasilkan lulusan sekuler jauh dari idealism Islam, Cara berfikir sekuler memisahkan urusan dunia dan urusan akhirat, bahkan menjauhkan nilai agama dalam sain dan teknologi. usaha-usaha memasukan nilai agama dalam dunia sain dan teknologi dipandang kampungan dan tak ilmiah.

2. Penolakan terhadap Modernitas

Pondok Pesantren al-Islam menilai pendidikan modern mengandung muatan negatif. ${ }^{16}$ Karena pendidikan modern berbasis pada ideology sekuler. al-Islam Tenggulun tak membedakan antara modernitas, westernisasi dan sekularisasi. Bagi Pondok Pesantren al-Islam, Ketiganya senapas dan seiring yakni sumber kekacauan masyarakat dan jika dibiarkan akan merusak cara berfikir anak-anak Islam.

Apa yang dimaksud dengan pendidikan moderen? Pendidikan Moderen adalah pendidikan yang menekankan pada cara berfikir dan bertindak rasional. Paham ini meminta agar anak didik bertindak efektif, efisien dan terprogram. Karenanya, paham ini bersifat rasional yakni kegiatan yang terukur dan seluruh tindakannya dapat dipertanggung

${ }^{21}$ Kuntowijoyo, Paradigma. 
jawabkan. Syarat pendidikan moderen adalah : berfikir logik, bertindak efektif dan efisien. Namun demikian, pendidikan modern yang berbasis pada filsafat modernitas meniadakan unsur agama dan ketuhanan. Agama dan Ketuhahanan adalah urusan individu masing-masing. Agama yang bersifat pribadi jangan dibawa pada urusan publik.

Sementara itu, westernisasi adalah kegiatan yang mengarahkan masyarakat agar meniru mentah-mentah masyarakat Barat, baik cara berfikir maupun bertindak. Masyakat Barat mengklaim diri lebih baik dan lebih maju dalam banyak sisi kehidupan. Peniruan ini meliputi berbagai aspek kehidupan: politik, social-masyarakat dan budaya. Inti westernisasi adalah sekularisasi.

Apa yang dimaksud dengan sekularisasi ? Sekularisasi yang marak tahun 70-an di Indonesia adalah paham yang menekankan dan mengajak agar manusia bertindak serta berfikir pada ke-kinian dan kedisinian. Menurut paham ini, hal yang pokok dalam hidup dan kehidupan adalah saat ini dan di sini. Kehidupan akhirat yang nun jauh di sana seperti ajaran agama, tidaklah penting. Perbaikilah kualitas hidup dan kehidupan manusia dengan bertindak rasional yang sekarang dan sedang di hadapi.

3. Membangun Supremasi Ajaran Islam

PP al-Islam membangun apa yang disebut sebagai, "Supremasi Ajaran Islam". Seluruh ajarannya adalah universal dan merupakan kebenaran yang datang dari Tuhan. Tiada unsur kehidupan maupun kematian yang terlepas dari nilai Islam. Islam harus diterima secara holistic.

Sementara itu ideology sekuler dalam pendidikan mengajarkan ide pemisahan antara agama dan negara atau masyarakat. Agama adalah urusan pribadi yakni hubungan antara individu dengan Tuhannya. Selain itu, ideology sekuler dalam pendidikan mengajarkan ide relatifisme agama. Jargon yang digunakan oleh idelogi sekuler ialah semua agama sama. Tidak ada agama yang lebih unggul dari yang lain. Lebih jauh, ideology sekuler mengatakan jangan membawa urusan agama ke wilayah public. Bagi mereka penganut ideologi sekuler, pendidikan Islam harus 
mau tunduk dan patuh pada cara berfikir sekuler. Sistem kehidupan social diatur berdasar pada kepentingan manusia dan kesepakatankesepakatan manusia semata. Wilayah transeden yang ilahi disingkirkan jauh-jauh dan itu hanya milik pribadi-masing-masing.

Dalam paradigma tauhid, pendidikan Islam membangun ide tentang kepercayaan pada Tuhan YME. Hal ini artinya, ajaran Islam berorientasi pada martabat atau keagungan manusia (human dignity). Namun demikian, keagungan manusia berbasis pada Ketuhanan. Dengan demikian, paradigma tauhid dalam pendidikan Islam berarti membangun keagungan manusia dalam bingkai Ketuhanan. Sisi keagungan manusia dalam ajaran Islam adalah manusia diberi mandat oleh Tuhan sebagai khalifah di muka bumi. Karena itu, posisi khalifah di atas bumi merupakan tugas-tugas mulia, di mana seluruh tindakannya harus dapat dipertanggung jawabkan di hadapan Tuhan sebagai pemberi mandat.

4. Mengembangan Humanisme Theocentris

Yang dimaksud dengan humanism theocentris adalah adalah pengakuan akan manusia sebagai mahluk yang bermartabat. Martabat manusia terletak pada existensi, hak-hak asasinya. Karena itu, eksistensi dan hak-hak asasi manusia mesti dilindungi. Lebih jauh maka asas pokok pendidikan dalam adalah Islam tak boleh melanggar hak-hak tersebut. Pelanggaran terhadap eksistensi dan hak asasi merupakan penghianatan terhadap keagungan manusia. Bentuk eksistensi dan hak asasi dalam Islam adalah kesederajatan, seluruh manusia memiliki hak dan kewajiban asasi yang sama. Yang membedakan derajat manusia dihadapan Tuhan hanyalah taqwanya (QS. Al-Hujurat: 15$).^{22}$

Selain tekanan pada eksistensi dan hak asasi manusia, paradigma pendidikan Islam juga memperhatikan kesatuan umat manusia. Perbedaan suku, ras, bahasa dan agama tak menjadi halangan untuk mewujudkan kasatuan manusia. Prinsip ini memberikan dasar tentang nasib ummat manusia. Hal-hal yang terkait dengan ketimpangan kesejahteraan, keselamatan dan keamanan manusia menjadi sangat

${ }^{22}$ Kementerian Agama RI., Al-Qur'an. 
penting. Masalah-masalah tersebut tak cukup diselesaikan oleh sekelompok orang atau bangsa. Acuh atau tutup mata terhadap masalah ini adalah kejahatan kemanusiaan. 23

\section{E. Paradigma Tauhid : Formulasi ideologi pendidikan Islam.}

al-Islam Tenggulun memandang bahwa Islam bukan sekedar doktrin keagaman yang mengatur hubungan manusia dengan Tuhan. Lebih dari itu, Islam mengandung ajaran yang kompleks. Di dalam Islam terkandung ajaran membangun pribadi yang shaleh, menata kehidupan keluarga dan masyarakat, baik secara pendidikan, ekonomi maupun politik. Karena itu, Islam adalah jawaban terhadap persoalan-persoalan kemanusiaan secara luas. Agar Islam dapat terwujud dalam kehidupan nyata, maka Islam harus diperjuangkan oleh individu maupun kelompok. Islam sebagai jawaban terhadap persoalan-persoalan manusia, maka Islam mengandung ajaran-ajaran yang berbeda dengan ideology-ideologi besar; kapitalisme, sosialisme dan komunisme. Dalam perjalanan sejarahnya, Islam telah ikut serta menyumbang para peradaban dunia. Islam merupakan totalitas seluruh dimensi kehidupan, yang tak pernah ditemukan dalam ideology manapun. Islam bemaksud membangun proyek raksasa kemanusiaan yang dilandasi oleh nilai Islam. Demikianlah, Pesantren al-Islam bermaksud menghadirkan pendidikan yang Islami. Atinya pendidikan yang sepenuhnya dilandasi oleh nilai-nilai Islam.

Dalam hal ideology pendidikan, Pondok Pesantren al-Islam mengembangkan paradigm tauhid. Hal ini artinya menempatkan tauhid sebagai sentral pendidikan. Inti pendidikan Islam adalah terbentuknya jiwa tauhid. Implementasi pendidikan dalam Pondok Pesantren al-Islam, melalui tiga tahap, Tiga tahap tersebut adalah tarbiyah, hijrah dan jihad.

Dalam tahap tarbiyah, seorang santri dididik untuk mengetahui dan menyadari esksistensi manusia di muka bumi. Eksistensi manusia di muka bumi adalah sebagai khalifah fil ardhi dan hamba Allah swt. Allah swat telah membekali manusia dengan kemampuan akalnya sebagai bekal untuk melaksanakan tugas-tugas kekhalifahan. Tugas-tugas kekhalifahan

${ }_{23}$ Taufik Nugroho, "Pendidikan Karakter Dalam Al-Qur'an (Studi Tafsir Pendidikan Surat Luqman)," Jurnal Ulumuddin 4, no. 1 (2014): 14-22. 
dimuka mesti didukung oleh kemampuan manusia untuk membaca ; fenomena alam; menamai, nenyimpulkan dan memberikan pemecahan masalah. Tahap berikutnya dalam tarbiyah adalah kemampuan manusia untuk membaca; fenomena alam; menamai, nenyimpulkan dan memberikan pemecahan masalah. Tahap berikutnya dalam tarbiyah adalah internalisasi nilai. Yang dimaksud dengan internalisasi nilai adalah proses nilai-nilai yang diperoleh melalui membaca diresapi dan merembes pada diri para santri, sehingga nilai-kekhalifahan dan kehambaan berbasis tauhid menjadi miliki pribadi santri. Seluruh tindakannya berorientasi ada tugas kekahlifahan dan kehambaan.

Jika seorang santri sudah menghayati nilai-nilai kekhalifahan dan penghambaan kepada Allah swt. Inilah yang disebut dengan hijrah. Yakni aktivitas pergerakan dari kehidupan non-Islami menjadi kehidupan yang sepenuhnya Islam atau disebut dengan Islam kaffah.

Tahap terakhir dari pendidikan Islam adalah jihad. Proses ini dilalui oleh seorang santri ketika memposisikan dirinya di masyarakat atau dimensi sosial. Jihad dalam perspektif Pondok Pesantren al-Islam, Tenggulun adalah aktivitas manusia di masyarakat dalam rangka menegakan ajaran Islam. Seorang muslim yang berjihad adalah seorang yang dengan sekuat tenaga menegakan ajaran Islam untuk diri sendiri maupun untuk masyarakat. Visi seorang muslim di masyarakat komitmen melaksanakan ajaran Islam; amar ma'ruf nahi mungkar (mengajak kepada kebaikan dan mencegah kemungkaran).

\section{F. Penutup}

Pondok Pesantren al-Islam Tenggulun membangun tauhid sebagai standar nilai. Yang dimaksud dengan tauhid sebagai standar nilai adalah bahwa tauhid ditempatkan referensi pemikiran, sikap dan tindak manusia. Apapun pemikiran dan sikap atau tindakan manusia muslim menjadikan tauhid sebagai referensi utama untuk menilai apakah tindakan tersebut taat asas atau keluar dari asas.

Implementasi pendidikan Islam Kaffah dalam Pesantren al-Islam, melalui tiga tahap, tiga tahap tersebut adalah tarbiyah, hijrah dan jihad. Dalam tahap tarbiyah, seorang santri dididik untuk mengetahui dan 
menyadari esksistensi manusia di muka bumi. Tahap hijrah, yakni pendidikan santri yang sudah menghayati nilai-nilai kekhalifahan dan penghambaan kepada Allah swt dengan aktivitas pergerakan dari kehidupan non-Islami menjadi kehidupan yang sepenuhnya Islam aau disebut dengan Islam kaffah. Tahap terakhir dari pendidikan Islam dimana aktivitas manusia di masyarakat dalam rangka menegakkan ajaran Islam.

\section{Bibliography}

Althusser, Louis. For Marx. Translated by Ben Brewster. New York: Pantheon, 1969.

-- - Tentang Ideologi, Marxisme Strukturalis, Psikoanalisis, Cultural Studies. Translated by Olsy Vinoly Arnof. yogyakarta: Jalasutera, 2008.

Creswell, John W. Qualitayive Inquiry and Research Design: Choosing Among Five Traditios. London: Sage Publication Ltd., 1988.

Direktorat Jenderal Pembinaan Kelembagaan Agama Islam. Pondok Pesantren Dan Madrasah Diniyah Pertumbuhan Dan Perkembangannya. Departemen Agama RI, Direktorat Jenderal Kelembagaan Agama Islam, 2003.

Gamson, William. "Political Discourse and Collective Action." In From Structure to Action, Campaign Social Movement Across-Culture, edited by B. Klandersman, H. Kriesi, and S. Torrow, 219-255. Greenwich: International Social Movement Research Press, 1988.

Hasan, Noorhaidi. Laskar Jihad. Jakarta: LP3ES-KITLV, 2008.

Imroatun, Imroatun. "Kontribusi Lembaga Pendidikan Agama Islam Dalam Penguatan Identitas Bangsa." Jurnal Ilmiah Bidang pendidikan Studia Didaktika 8, no. 1 (2016).

Kementerian Agama RI. Al-Qur'an Dan Terjemahnya. Jakarta: PT.Sinergi Pustaka Indonesia, 2012.

Kiki, Rakhmad Zailani. Genealogi Intelektual Ulama Betawi: Melacak Jaringan Ulama Betawi Dari Abad Ke-19 Sampai Abad Ke-21. Jakarta: Jakarta Islamic Centre, 2011.

Kuntowijoyo. Paradigma Islam, Interpretasi Untuk Aksi. Bandung: Mizan, 1991.

Musaropah, Umi. "Kharisma Kyai Dalam Organisasi Pendidikan Pesantren Tradisional." Ulumuddin: Jurnal Ilmu-ilmu Keislaman 8, no. 2 (2018): 141-155.

- - . "Pendidikan Kebangsaan Dalam Pesantren Perspektif Abdul Wahid Hasyim.” Ulumuddin: Jurnal Ilmu-ilmu Keislaman 9, no. 1 (2019): 1-22.

Nugroho, Taufik. "Pendidikan Karakter Dalam Al-Qur'an (Studi Tafsir Pendidikan Surat Luqman).” Jurnal Ulumuddin 4, no. 1 (2014): 1422.

- - . "Reorientasi Peranan Pesantren Pada Era Pembangunan Menuju Partisipasi Pemberdayaan Masyarakat Bawah.” Ulumuddin : Jurnal 
Ilmu-ilmu Keislaman 7, no. 2 (2017): 147-155.

Prihantoro, Agung, and Fattah Hidayat. "Melakukan Penelitian Tindakan Kelas.” Ulumuddin : Jurnal Ilmu-ilmu Keislaman 9, no. 1 (2019): 4960.

Shariati, Ali. Man and Islam. Translated by Fatollah Marjani. Houston USA: Free Islamic Literature, 1981.

Shmuel Bar. “The Religious Sources of Islamic Terrorism.” Last modified 2004. https://www.hoover.org/research/religious-sources-islamicterrorism.

Sofwan, Rinaldy. "Keluarga Amrozi Dan Jihad Yang Tertunda Dari Lamongan." CNN Indonesia, January 17, 2017.

Thompson, John B. Analisis Ideologi: Kritik Wacana Ideologi-Ideologi Dunia. Translated by Haqqul Yakin. Yogyakarta: IRCiSoD, 2003.

Tilaar, H.A.R. Kekuasaan Dan Pendidikan: Suatu Tinjauan Dari Perspektif Studi Kultural. Magelang: Indonesia Tera, 2003. 
Taufik Nugroho

112 Ulumuddin: Jurnal IImu-ilmu Keislaman, Vol. 9, No. 2, Desember 2019 